\title{
Sowing seeds of faith
}

\section{Maria Júlia Paes da Silva ${ }^{1}$}

During my years as scientific editor I was given the opportunity to participate in several journal discussion forums. One of the main complaints presented in those discussions was the poor acknowledgement of that position. As an editor, it is necessary to learn what is involved in following manuscript check-lists, manuscript flow, pagination, converting to html, SciELO markup, controlling subscriptions, expedition of the editions and ... there is no reward, in terms of CAPES (Coordination for the Improvement of Higher Education Personnel, abbreviation in Portuguese) scoring, that matched the magnitude of this task.

As scientific editor at REEUSP I had the chance to follow the development of its board of ad-hoc consultants (differentiated!), the increase in the number of article submissions (with more and more quality!), its indexation in the main health area databases (ISI, MEDLINE, SCOPUS, SCIELO, LILACS, CINAHL, CUIDEN PLUS, LATINDEX, PERIÓDICA: INDEX OF LATIN AMERICAN JOURNALS IN SCIENCES, CUIDATGE, Rev@Enf and BDENF), the institutional support policy for the journal project, the changes made to its layout, its inclusion in the electronic publishing process and its development in the country, with publications from every Brazilian region.

Also as scientific editor I realized the need to charge subscriptions and prepare and train referees, in addition to the dependence on new sources for financial support to reduce the burden to authors regarding the costs of bilingual or trilingual publication. As editor with the journal of the University of São Paulo School of Nursing, considerable investments were made to maintain the volume of publications of articles by authors of states other than São Paulo (one of the criteria by which we were evaluated is that $60 \%$ of the articles originate out of Sao Paulo), to maintain $80 \%$ of publications as original research articles, to always make peer review a transparent process, used by the journal, comparing it to processes adopted by other national and international journals in the health area.

During those years, while learning to grow and constantly improve, efforts were made to establish partnerships between journals, and hold events that would join journals published in Spanish and Portuguese. In addition, we participated in ABEC (Brazilian Scientific Editors Association) meetings and training programs to learn how to use SciELO Method Programs, disseminated the journal's capacity in national and international events, followed the classification of REEUSP on CAPES: International $C$, International $B$ and International $A 2$.

We continue alert regarding its scientific character, its periodicity and punctuality, the clarity of normalization, the performance evaluation criteria for remaining on the databases, the construction of adequate impact indicators for each journal title.

We currently implemented an Online SciELO manuscript publication-submission system, and count on compromised and skilled personnel, with publications of acknowledged authors and, what is also essential: making a difference in the profession by helping disseminate state of the art studies, which have been changing and improving professional practice.

Concluding my activities as Scientific Editor at REEUSP, I reiterate the belief that editors work hard, learn a great deal, are not properly acknowledged for their work, but, when their task is concluded, they can affirm:

I have fought a good fight, I have finished my course, I have kept the faith (2 Tim 4,7). Faith in the profession, faith in colleagues, today and tomorrow, with the certainty that it is always possible to improve.

${ }^{1}$ Nurse. Full Professor of Medical-Surgical Nursing Department at School of Nursing at University of São Paulo. Director of Nursing Department at São Paulo University Hospital. São Paulo, SP, Brazil. juliaps@usp.br 